Electron Bernstein Wave Electron Temperature Profile Diagnostic

by

G. Taylor, P. Efthimion, B. Jones, T. Munsat, J. Spaleta, J. Hosea, R. Kaita, R. Majeski, and J. Menard

July 2000

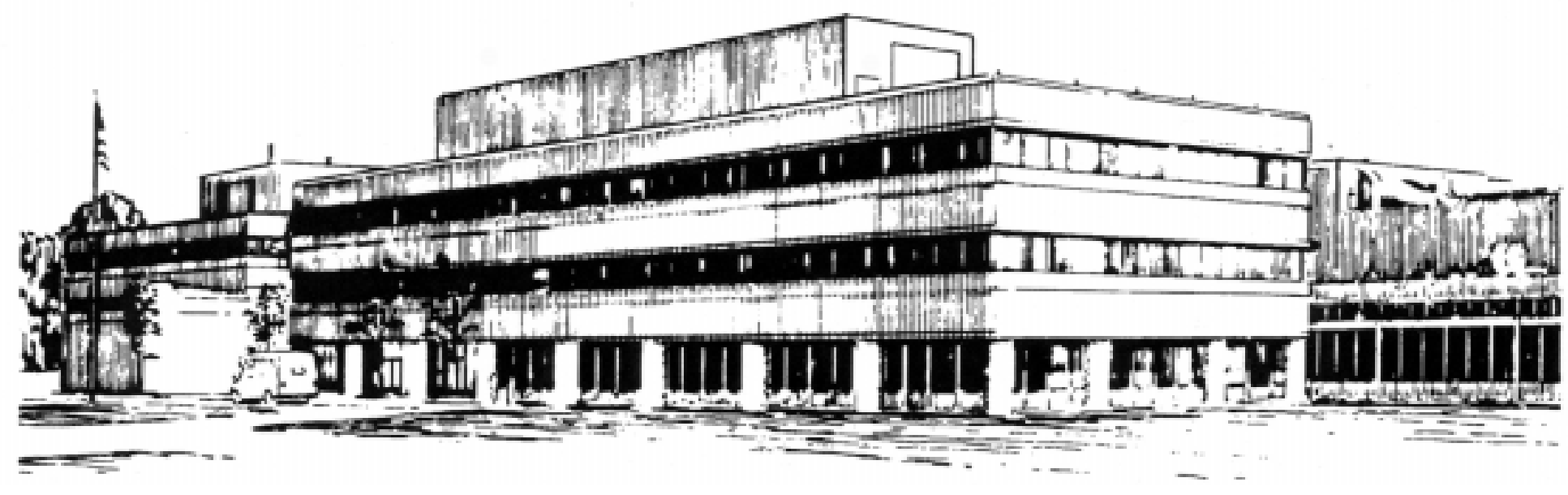

PRINCETON PLASMA PHYSICS LABORATORY PRINCETON UNIVERSITY, PRINCETON, NEW JERSEY 


\section{PPPL Reports Disclaimer}

This report was prepared as an account of work sponsored by an agency of the United States Government. Neither the United States Government nor any agency thereof, nor any of their employees, makes any warranty, express or implied, or assumes any legal liability or responsibility for the accuracy, completeness, or usefulness of any information, apparatus, product, or process disclosed, or represents that its use would not infringe privately owned rights. Reference herein to any specific commercial product, process, or service by trade name, trademark, manufacturer, or otherwise, does not necessarily constitute or imply its endorsement, recommendation, or favoring by the United States Government or any agency thereof. The views and opinions of authors expressed herein do not necessarily state or reflect those of the United States Government or any agency thereof.

\section{Availability}

This report is posted on the U.S. Department of Energy's Princeton Plasma Physics Laboratory Publications and Reports web site in Calendar Year 2000. The home page for PPPL Reports and Publications is: http://www.pppl.gov/pub_report/

DOE and DOE Contractors can obtain copies of this report from:

U.S. Department of Energy

Office of Scientific and Technical Information

DOE Technical Information Services (DTIS)

P.O. Box 62

Oak Ridge, TN 37831

Telephone: (865) 576-8401

Fax: (865) 576-5728

Email: reports@adonis.osti.gov

This report is available to the general public from:

National Technical Information Service

U.S. Department of Commerce

5285 Port Royal Road

Springfield, VA 22161

Telephone: $1-800-553-6847$ or

(703) $605-6000$

Fax: (703) 321-8547

Internet: http://www.ntis.gov/ordering.htm 


\title{
Electron Bernstein Wave Electron Temperature Profile Diagnostic
}

\author{
G. Taylor, P. Efthimion, B. Jones, T. Munsat, J. Spaleta, J. Hosea, \\ R. Kaita, R. Majeski, J. Menard \\ Plasma Physics Laboratory, Princeton University, \\ Princeton, New Jersey 08543
}

\begin{abstract}
Electron cyclotron emission (ECE) has been employed as a standard electron temperature profile diagnostic on many tokamaks and stellarators, but most magnetically confined plasma devices cannot take advantage of standard ECE diagnostics to measure temperature. They are either "overdense", operating at high density relative to the magnetic field (e.g. $\omega_{\mathrm{pe}} \gg \Omega_{\mathrm{ce}}$ in a spherical torus) or they have insufficient density and temperature to reach the blackbody condition $(\tau>2)$. Electron Bernstein waves (EBWs) are electrostatic waves that can propagate in overdense plasmas and have a high optical thickness at the electron cyclotron resonance layers, as a result of their large $\mathrm{k}_{\text {perp }}$. This paper reports on measurements of EBW emission on the CDX-U spherical torus, where $\mathrm{B}_{\mathrm{o}} \sim 2 \mathrm{kG},\left\langle\mathrm{n}_{\mathrm{e}}\right\rangle$ $\sim 10^{13} \mathrm{~cm}^{-3}$ and $\mathrm{T}_{\mathrm{e}} \approx 10-200 \mathrm{eV}$. Results are presented for electromagnetic measurements of EBW emission, mode-converted near the plasma edge. The EBW emission was absolutely calibrated and compared to the electron temperature profile measured by a multipoint Thomson scattering diagnostic. Depending on the plasma conditions, the modeconverted EBW radiation temperature was found to be $\leq T_{e}$ and the emission source was determined to be radially localized at the electron cyclotron resonance layer. A Langmuir triple probe and a $140 \mathrm{GHz}$ interferometer were employed to measure changes in edge density profile in the vicinity of the upper hybrid resonance where the mode conversion of the EBWs is expected to occur. Initial results suggest EBW emission and EBW heating are viable concepts for plasmas where $\omega_{\mathrm{pe}}>\Omega_{\mathrm{ce}}$.
\end{abstract}




\section{INTRODUCTION}

For over twenty years the measurement of electron cyclotron emission (ECE) from magnetically confined plasmas has been an important diagnostic technique for the measurement of the local electron temperature. The first measurements of ECE were made in the early 1970s by Costley et al ${ }^{1}$. The potential for using the ECE spectrum to diagnose plasmas was suggested by Engelmann and Curatolo ${ }^{2}$ and Celata and Boyd ${ }^{3}$. A review of ECE physics and the diagnostic potential of ECE can be found in Bornatici et al ${ }^{4}$. However, many magnetically confined plasmas cannot take advantage of standard ECE diagnostics. These plasmas are either "overdense", that is, they are operated at too high a density relative to their magnetic field (e.g. $\omega_{\mathrm{pe}} \gg \Omega_{\mathrm{ce}}$, where $\omega_{\mathrm{pe}}$ is the electron plasma frequency and $\Omega_{\mathrm{ce}}$ is the electron cyclotron frequency), or they do not have sufficient temperature and density to reach the blackbody condition $(\tau>2$, where $\tau$ is the optical depth).

Electron Bernstein waves (EBWs) ${ }^{5}$ are electrostatic waves that propagate in overdense plasmas and are strongly absorbed at the location of the electron cyclotron resonant layers. Because EBWs are electrostatic waves, with a large wavenumber $\left(\mathrm{k}_{\text {perp }}\right)$, their optical thickness at the electron cyclotron resonance locations can be extremely high. For example, in the CDX- $\mathrm{U}^{6}$ spherical torus at Princeton $\left(\mathrm{B}_{\mathrm{o}} \sim 2 \mathrm{kG},\left\langle\mathrm{n}_{\mathrm{e}}>\sim 10^{13} \mathrm{~cm}^{-3}\right.\right.$ and $\mathrm{T}_{\mathrm{e}} \approx 10-200$ $\mathrm{eV}), \tau \sim 300$ at the electron cyclotron resonant layers ${ }^{7}$. EBWs are therefore strongly coupled to the plasma at the cyclotron resonances, the same condition that exists for ECE electromagnetic waves below the cutoff density in many tokamaks and stellarators. However, unlike ECE, EBWs cannot propagate beyond the upper hybrid resonance (UHR) layer that surrounds an overdense plasma. The UHR frequency being given by:

$$
\omega_{U H}=\sqrt{\Omega_{c e}^{2}+\omega_{p e}^{2}}
$$

Other than direct measurement of the EBWs with an electrostatic probe or antenna, there are two possible indirect measurement scenarios involving the mode conversion of EBWs to electromagnetic emission. Indeed, early extraordinary mode (X-mode) fundamental ECE measurements by Hosea, Arunasalam and Cano ${ }^{8}$ on PLT were attributed to thermal excitation of EBWs, which subsequently mode convert to electromagnetic waves. In one mode conversion and tunneling process, illustrated schematically in Fig. 1(a), 
the EBWs mode convert to the slow X-mode at the UHR layer, and follow the slow Xmode branch to the left hand cutoff, given by:

$$
\omega_{L}=\frac{1}{2}\left[\left(\Omega_{c e}^{2}+\frac{4 \omega_{p e}^{2}}{1-n_{/ /}^{2}}\right)^{1 / 2}+\Omega_{c e}\right]
$$

Where $\mathrm{n}_{/ /}$is the index of refraction parallel to the magnetic field. At the left hand cutoff the waves reflect back towards the UHR layer. At the UHR layer, the waves are once again converted to EBWs. We will refer to this as the B-SX-FX process. This process normally traps the EBW radiation within the UHR surface, which surrounds the plasma. However, if the density gradient is sufficiently steep at the location of the UHR layer, the UHR layer can come close enough to the right hand cutoff, given by:

$$
\omega_{R}=\frac{1}{2}\left[\left(\Omega_{c e}^{2}+\frac{4 \omega_{p e}^{2}}{1-n_{/ /}^{2}}\right)^{1 / 2}-\Omega_{c e}\right]
$$

so that some of the power trapped in the plasma can tunnel through to the fast, electromagnetic, X-mode branch. This is the mode conversion process we initially set out to study on CDX-U. In the other mode conversion process, illustrated schematically in Fig. 1(b), an oblique viewing angle to the magnetic field changes $n_{/ /}$so that the left hand cut off moves close to the ordinary mode (O-mode) cutoff $\left(\omega_{\mathrm{pe}}\right)$. The slow X-mode then couples directly to the electromagnetic $\mathrm{O}$-mode. This process, originally proposed by Preinhaelter and Kopecky ${ }^{9}$ for electron cyclotron resonance heating, was successfully used by Laqua et al. ${ }^{10}$ to measure EBW emission on the W7-AS stellarator.

Figure 2 illustrates the typical frequency ranges relevant to our mode-converted EBW emission measurements on $\mathrm{CDX}-\mathrm{U}$, for the $\mathrm{B}_{\mathrm{o}}=2.1 \mathrm{kG}$ plasmas presented here. $\mathrm{CDX}-\mathrm{U}$ has a major radius of $34 \mathrm{~cm}$ and the last closed flux surface on the outboard midplane is at a major radius of $56 \mathrm{~cm}$. Figure 2 shows the radial dependence of the first three ECE harmonics for a typical plasma current of $70 \mathrm{kA}$. The data presented here were acquired with radiometers which measured frequencies indicated by the shaded region in Fig. 2. This frequency range corresponds to the second ECE harmonic. Also shown in this figure is the radial dependence of the right and left hand cutoff frequencies, the UHR frequency and the electron plasma frequency. These frequencies were calculated using measured electron 
density from Abel-inverted microwave interferometer data and a Langmuir triple probe, which was radially scanned near the last closed flux surface. The UHR layer, where the mode conversion of the second harmonic EBW emission occurs is located near the last closed flux surface at the outboard edge of the plasma. It should be noted that the highest frequencies measured by our radiometers are resonant with the third electron cyclotron layer near the the plasma edge. If the upper hybrid layer is outside the location of this resonance, second harmonic EBW will not be able to propagate past the third harmonic resonance.

Section II of this paper discusses the design of the EBW diagnostic. Section III presents some of the mode-converted EBW emission measurements on CDX-U, and Section IV is a discussion of our results and our future plans for EBW measurements on the CDX-U and NSTX $^{11}$ spherical tori.

\section{EBW DIAGNOSTIC DESIGN}

Since the magnetic fields in spherical tori, such as CDX-U and NSTX, are relatively low $(\leq 6 \mathrm{kG})$, the characteristic emission frequency for fundamental or second harmonic EBWs is $\leq 40 \mathrm{GHz}$. In this frequency range, microwave components are relatively inexpensive and have very low noise characteristics. Either multi-channel or fast scanning heterodyne radiometer designs, which have been well established at much higher frequencies $^{12}$, can be readily implemented at these lower frequencies. We used two types of antenna design; a polarization insensitive, cavity-backed, 2-18 $\mathrm{GHz}$ spiral antenna and a polarized, notched waveguide, horn antenna which can be used up to $40 \mathrm{GHz}$. The spiral antenna had a large acceptance angle, with $-3 \mathrm{~dB}$ points at \pm 45 degrees. The notched waveguide antenna had a much narrower field of view with $-3 \mathrm{~dB}$ points at \pm 14 degrees. The antennas were mounted to have a horizontal, major radial view, on or just below the midplane of CDX-U, and they were mounted outside the vacuum, viewing the plasma through a fused silica or BK-7 vacuum window. Broadband, flexible, coaxial cable, with relatively low loss up to $18 \mathrm{GHz}$, connected the antennas to the radiometers.

Three types of heterodyne radiometer were used for our CDX-U EBW measurements: two tunable radiometers could be tuned between plasma shots, the other, a fast scanning, 7.2-12.4 GHz radiometer, could measure the EBW spectrum every $20 \mu \mathrm{sec}$. Figure 3(a) shows a schematic diagram of one of the tunable radiometers. The microwave section used a broadband, 4-18 GHz, double balanced, second harmonic mixer and the local oscillator signal was provided by a 4-6 GHz, permanent magnet, YIG-tuned oscillator. The other 
tunable receiver used a 2-26 GHz second harmonic, double balanced mixer and an 8-12.5 $\mathrm{GHz}$ YIG-tuned oscillator. YIG oscillators have a linear voltage-to-frequency characteristic, but typically take $\sim 10 \mathrm{msec}$ to tune within their spectral range. For CDX-U, which is a relatively short pulse machine $(<20 \mathrm{msec})$, spectral profiles have to be built up over many similar plasma discharges. An isolator reduces leakage of local oscillator power out of the antenna, which, if not suppressed, can result in coherent homodyning artifacts in the radiometer output. The intermediate frequency section has two stages of amplification separated by a $0-60 \mathrm{~dB}$ step attenuator. A $100-200 \mathrm{MHz}$ bandpass filter defines the frequency resolution of the receiver. Since this is a double sideband design, the instrument frequency resolution is $400 \mathrm{MHz}$, resulting in a typical major radial resolution in the plasma of $2-3 \mathrm{~cm}$. The final receiver stage is the video detection and amplification section that has $-3 \mathrm{~dB}$ bandwidth of $1 \mathrm{MHz}$. Figure 3(b) shows a schematic diagram of the fast scanning radiometer. The microwave section uses a broadband, 2-26 GHz, double balanced, fundamental mixer and a local oscillator signal provided by a 7.2-12.4 GHz voltage controlled oscillator (VCO). Although this type of oscillator has a nonlinear voltage-tofrequency characteristic, it has a frequency settling time of $<50 \mathrm{nsec}$ within its operational frequency range. For our measurements on CDX-U, we scanned the VCO over its full frequency range every $20 \mu \mathrm{sec}$. In this radiometer, a low noise microwave pre-amplifier amplifies the received signal prior to the mixing stage, this reduces the amplification necessary in the intermediate frequency stage and improves the overall receiver signal-tonoise ratio. Otherwise, the receiver frequency resolution and video section are similar to the tunable receivers described earlier.

The EBW radiation temperatures, $\mathrm{T}_{\text {rad }}$, quoted in this paper are derived from an absolute calibration of the diagnostic sensitivity. The EBW radiometers, including the antennas, microwave cables, and the vacuum window material, were calibrated absolutely, in-situ, using a Dicke switching ${ }^{13}$ calibration technique. The calibration employed Eccosorb $\mathrm{CV}$ immersed in liquid nitrogen, combined with a mechanical radiation chopper, as the calibration source. The minimum detectable radiation temperature was determined to be about $0.1 \mathrm{eV}$ and receiver responsivity was typically in the range of $5 \times 10^{-2} \mathrm{VeV}^{-1}$.

\section{EBW MEASUREMENTS}

Most of the EBW data presented here were measured using one of the two frequency tunable heterodyne radiometers (Fig. 3(a)). Measurements of the $\mathrm{T}_{\text {rad }}(\mathrm{R})$ profile were therefore acquired over many, relatively similar, discharges, and as a result, the quality of 
the $\mathrm{T}_{\text {rad }}(\mathrm{R})$ profile measurements was degraded due to shot-to-shot variability. We only recently began using a fast scanning EBW radiometer (Fig. 3(b)) allowing us to measure the evolution of the EBW $\mathrm{T}_{\text {rad }}$ profile on a single plasma shot. Figure 4 shows the time evolution of major plasma parameters during a typical CDX-U plasma with $\mathrm{B}_{\mathrm{o}}=2.1 \mathrm{kG}$. The plasma current, shown in Fig. 4(a), rises to about $70 \mathrm{kA}$ at $221 \mathrm{msec}$. At the time of peak plasma current, the line average electron density, measured by a microwave interferometer viewing a vertical chord close to the plasma major radius, (Fig. 4(b)) reaches about $1 \times 10^{13} \mathrm{~cm}^{-3}$. Figures 4(c) and 4(d) show the time evolution of the electron density and temperature, respectively, as measured by a Langmuir triple probe located at $\mathrm{R}=58$ $\mathrm{cm}, 2 \mathrm{~cm}$ outside the last closed flux surface. At this location, the electron density, as measured by the probe, is in the range $1-2 \times 10^{12} \mathrm{~cm}^{-3}$ and the electron temperature is about $10 \mathrm{eV}$. Figure 4(e) shows the time evolution of the mode-converted EBW emission at 10.8 $\mathrm{GHz}$, a frequency which is resonant with the second harmonic electron cyclotron layer at $\mathrm{R}$ $=36 \mathrm{~cm}$, near the plasma axis. Electromagnetic waves at $10.8 \mathrm{GHz}$ are cutoff for electron densities greater than $9 \times 10^{11} \mathrm{~cm}^{-3}$, so for these discharge parameters the plasma is well into the overdense regime at the plasma axis, and is often overdense out to the last closed flux surface. The EBW $\mathrm{T}_{\text {rad }}$ increases from $10 \mathrm{eV}$ at $217 \mathrm{msec}$ to about $60 \mathrm{eV}$ at $222 \mathrm{msec}$. Typically there are large fluctuations on the mode-converted EBW signal, with a $\Delta \mathrm{T}_{\mathrm{rad}} / \mathrm{T}_{\mathrm{rad}}$ $\sim 30 \%$, as can be seen in Fig. 4(e). These fluctuations may be due to the edge density fluctuations (Fig. 4(c)) affecting the mode conversion efficiency.

In order to build up an $\mathrm{EBW} \mathrm{T}_{\text {rad }}(\mathrm{R})$ profile, the $\mathrm{EBW}$ radiometer receive frequency was tuned over a sequence of about $60 \mathrm{CDX}-\mathrm{U}$ discharges similar to the one shown in Fig. 4. Since the time between CDX-U shots is about 5-6 minutes, this represents about 5-6 hours of CDX-U operation. During this frequency scan, a multi-point Thomson scattering diagnostic acquired electron temperature data at one of several different times during each of these plasmas. The EBW radiometer measures $\mathrm{T}_{\mathrm{rad}}(\mathrm{R})$ on the horizontal midplane, and the Thomson scattering diagnostic measures the electron temperature profile vertically at $\mathrm{R}=35$ cm. To compare $\mathrm{T}_{\mathrm{e}}(\mathrm{Z})$ Thomson scattering data to $\mathrm{EBW} \mathrm{T}_{\mathrm{rad}}(\mathrm{R})$ data, the Thomson scattering data were flux surface mapped onto the horizontal midplane on both the inboard and outboard side of the plasma axis using the J-Solver code ${ }^{14}$. J-Solver is a fixedboundary, single-fluid, ideal MHD equilibrium solver. The $T_{e}(Z)$ to $T_{e}(R)$ mapping was found to be very sensitive to the Shafranov shift and the vertical position of the plasma axis. To improve the signal-to-noise, the Thomson scattering data were averaged over about ten similar shots. Fig. 5(a) shows a comparison between the Thomson scattering $\mathrm{T}_{\mathrm{e}}(\mathrm{R})$ profile and the EBW $\mathrm{T}_{\text {rad }}(\mathrm{R})$ profile at $217 \mathrm{msec}$, the first time marked by the vertical shaded 
region in Fig. 4. The Thomson scattering data were taken at $217 \mathrm{msec}$ and the EBW data were averaged between 216.5 and $217.5 \mathrm{msec}$, in order to time-average the effect of the fluctuations mentioned earlier. Note that the Thomson scattering mapped inboard of $\mathrm{R}=35$ $\mathrm{cm}$ are the same data points as those mapped outboard of $\mathrm{R}=35 \mathrm{~cm}$. The error bars on the EBW data are dominated by fluctuations in the plasma emission, and not by radiometer instrumental noise. It should also be noted that details of the port geometry used for the EBW measurement for this comparison may not have been entirely simulated in the calibration, so systematic errors of up to $20 \%$ may have been introduced into the deduced EBW $\mathrm{T}_{\text {rad }}$. Near the plasma axis, $\mathrm{R}=35 \mathrm{~cm}, \mathrm{~T}_{\mathrm{rad}}(\mathrm{R}) / \mathrm{T}_{\mathrm{e}}(\mathrm{R}) \sim 0.2$. While at $\mathrm{R}=44 \mathrm{~cm}$, $\mathrm{T}_{\mathrm{e}}(\mathrm{R}) / \mathrm{T}_{\mathrm{rad}}(\mathrm{R}) \sim 0.9$. Fig. $5(\mathrm{~b})$ shows a comparison between the $\mathrm{T}_{\mathrm{e}}(\mathrm{R})$ profile from the Thomson scattering diagnostic and the $\mathrm{T}_{\text {rad }}(\mathrm{R})$ from the EBW radiometer at $222 \pm 0.5 \mathrm{msec}$, the second time marked by vertical shaded region in Fig. 4. At this later time, $\mathrm{T}_{\text {rad }}(\mathrm{R}) \sim$ $\mathrm{T}_{\mathrm{e}}(\mathrm{R})$ at most radial locations where Thomson scattering data were available. However, the Thomson scattering data implies a hollow profile, whereas the $\mathrm{EBW} \mathrm{T}_{\text {rad }}(\mathrm{R})$ profile is clearly peaked near the plasma axis.

An important aspect of the mode-converted EBW emission is the degree of radial localization of the source of the emission. This was determined using a technique similar to that of Laqua et al ${ }^{10}$. A gas injector introduced a series of short gas puffs at the outboard midplane throughout the plasma pulse. A Langmuir triple probe located at $\mathrm{R}=58 \mathrm{~cm}$, just outside the last closed flux surface, measured a series of electron temperature oscillations, with the peak of the oscillations occurring about $100 \mu$ s after the turn off of the gas puff, as shown in Fig. 6(a). Figure 6(b) shows the EBW radiometer signal when the receiver was tuned to a frequency corresponding to the second harmonic electron cyclotron resonance near the axis. There is clear evidence for a delay of several hundred microseconds between the radiometer $\mathrm{T}_{\text {rad }}$ peak and the $\mathrm{T}_{\mathrm{e}}$ peak measured by the probe near the plasma edge. $\mathrm{A}$ sequence of similar plasmas was run with modulated gas puffing and the EBW radiometer receive frequency was tuned between shots. The modulation in the radiation temperature was measured by the EBW radiometer at each frequency. When data from all the radiometer receive frequencies were analyzed, an approximately linear increase in the delay to the $\mathrm{T}_{\text {rad }}$ peak as a function of decreasing plasma minor radius was observed. Figure 7 shows a plot of the time of peak EBW $\mathrm{T}_{\text {rad }}$ as a function of the major radius of the $\mathrm{EBW}$ emission (filled circles). The open circles indicate the time of the $\mathrm{T}_{\mathrm{e}}$ peak following the puff measured by the probe near the plasma edge $(R=58 \mathrm{~cm})$, for the same data set. For most of the plasmas in the dataset, the probe $\mathrm{T}_{\mathrm{e}}$ peaks $100 \pm 50 \mu \mathrm{s}$ after the gas puff turns off. When the delay measured in the EBW $\mathrm{T}_{\text {rad }}$ peak is linearly extrapolated out to the major 
radius of the probe, it agrees with the delay measured by the probe. The total time for the heat pulse to travel from the edge of the plasma to the plasma magnetic axis is $500 \mu \mathrm{s}$, similar to the plasma confinement time for these discharges. This value implies a particle diffusivity of about $10 \mathrm{~m}^{2} \mathrm{~s}^{-1}$ for this plasma regime.

We have recently acquired mode-converted EBW emission data with a fast scanning radiometer (Fig, 3(b)). This instrument can measure the $\mathrm{EBW} \mathrm{T}_{\text {rad }}(\mathrm{R})$ profile in less than $20 \mu$ s. EBW data were acquired during High Harmonic Fast Wave $(\mathrm{HHFW})^{15}$ heating experiments on CDX-U. Figure 8(a) shows a color contour plot of the time evolution of $\mathrm{T}_{\text {rad }}(\mathrm{R})$ for a plasma with ohmic heating only. The brightest emission is at $\mathrm{R} \sim 36 \mathrm{~cm}$, near the magnetic axis. The $\mathrm{T}_{\text {rad }}$ signal at $\mathrm{R} \geq 50 \mathrm{~cm}$ is probably fundamental $E B W$ emission from the inboard side of the plasma profile. Figure 8(b) shows EBW data for a similar plasma but with $54 \mathrm{~kW}$ of HHFW heating added between 218.7 and $221.7 \mathrm{msec}$. This plasma exhibits a much higher radiation temperature during the HHFW heating pulse. Figure 8(c) shows a color contour plot of the increase in $T_{\text {rad }}(R)$ during the HHFW pulse. The increase in $T_{\text {rad }}$ is broad, with the largest increase measured within $R=45 \mathrm{~cm}$. An analysis of the HHFW power deposition to the electrons with the TORIC ${ }^{16}$, full wave, RF power deposition code indicates that the bulk of the deposition to electrons is expected within a normalized minor radius, $\mathrm{r} / \mathrm{a} \sim 0.5$, qualitatively consistent with the $\mathrm{EBW} \mathrm{T}_{\text {rad }}$ data.

The received radiation from the B-SX-FX mode conversion process should be linearly polarized in the $\mathrm{X}$-mode, that is, perpendicular to the magnetic field direction at the outer plasma edge. As a result of the significant poloidal contribution to the total magnetic field at the outer plasma edge on CDX-U, the field pitch near the last closed flux surface is about 25 degrees to the horizontal at $\mathrm{I}_{\mathrm{p}} \sim 70 \mathrm{kA}$. Of course, this pitch will vary through the plasma pulse as the plasma current changes. In order to determine the degree of polarization of the EBW emission, two EBW radiometers were set up to simultaneously view the plasma with polarized notch waveguide, horn antennas. One radiometer was located on the horizontal midplane and the other $5 \mathrm{~cm}$ below the midplane. The antenna polarization sensitivity was determined in an earlier absolute calibration that used rotateable wire grids to measure the degree of polarization. In this calibration, the "X-mode" polarized source produced three times the signal of the "O-mode" polarized source. So for $100 \% \mathrm{X}$-mode polarized plasma emission we would expect the X-mode:O-mode ratio to be 3:1. Data were acquired at a receive frequency of $11.5 \mathrm{GHz}$ during a sequence of plasmas with either both antennas oriented in X-mode or with the antenna off the midplane in X-mode and the one on the 
midplane in O-mode, at the peak of the plasma current. Data from these polarization measurements are shown in Fig. 9(a). The ratio of the signal from the two radiometers is plotted versus time for sets of plasmas where both radiometers were set to measure Xmode (thin line), and where one radiometer measured X-mode and the other measured Omode (thick line). The shaded regions indicate the standard deviation in these ratios. Fig 9(b) illustrates how well matched the two datasets were in plasma current and line integral electron density. The $\mathrm{X}$-mode/X-mode ratio remains very close to unity (within 5\%) confirming that the two radiometers have a similar view of the plasma, even though the antennas are separated poloidally by about $5 \mathrm{~cm}$. Although there does appear to be some canonical difference between the $\mathrm{X}$-mode/O-mode ratio and the $\mathrm{X}$-mode/X-mode ratio, the difference is small $(\leq 20 \%)$. Clearly, these measurements do not show the linear X-mode polarization we expected. We will discuss the implication of these results further in the next section.

\section{SUMMARY DISCUSSION \& FUTURE PLANS}

Our results so far suggest that a mode-converted EBW radiometer may be a viable diagnostic for local electron temperature measurements in overdense plasmas. We have shown that it is possible, under certain conditions, to obtain mode-converted EBW radiation temperatures which are comparable to the electron temperature, that is, $\mathrm{T}_{\mathrm{rad}} / \mathrm{T}_{\mathrm{e}} \sim 1$. Further, we have demonstrated that the mode-converted EBW emission source is local to the electron cyclotron resonance layer and that the diagnostic exhibits good radial localization in a plasma discharge with a monotonic magnetic field gradient. The EBW diagnostic has been successfully applied to the study of particle transport in an overdense ST plasma device and initial results suggest that the diagnostic shows some promise for measuring the local HHFW RF power deposition to electrons.

However, there are several observations that need to be explained. First, the measured emission had little or no polarization in contrast to the expected linear, X-mode polarization. One possible reason for the lack of polarization may be that a significant fraction of the radiation entering the antenna has undergone polarization mixing due to multiple reflections between the vessel wall and the right hand cutoff. The notched waveguide antenna has a relatively large acceptance angle, with the antenna sensitivity dropping by only $3 \mathrm{~dB}$ at \pm 14 degrees from the antenna axis, so we might reasonably expect that some of this reflected emission is entering the antenna. It is also possible that the O-mode mode conversion process is contributing to the measured signal, we are presently investigating this 
possibility. Second, it is not yet clear that the observed $\mathrm{T}_{\mathrm{rad}} / \mathrm{T}_{\mathrm{e}}$ (Fig. 5) can be fully explained as resulting from the B-SX-FX mode conversion and tunneling process. This is further complicated by the sensitivity of the Thomson scattering $T_{e}(R)$ mapping to the Shafranov shift and plasma vertical position, and the observed lack of polarized emission. As mentioned earlier, the B-SX-FX emission process depends on there being a relatively steep density gradient at the UHR to allow the mode-converted emission to tunnel through to the right hand cutoff on the low field side of the plasma. There have been a number of papers that propose a heating scenario that uses the inverse of the B-SX-FX modeconversion process ${ }^{17-20}$. For the FX-SX-B heating scenario, the power that tunnels from the right hand cutoff to the UHR is assumed to be completely mode converted to EBWs. The maximum mode conversion efficiency, $C_{\max }$, is given by

$$
C_{\max }=4 e^{-\pi \eta}\left(1-e^{-\pi \eta}\right)
$$

where $\eta$ is the Budden tunneling parameter ${ }^{21}$. When the density scale length $L_{n}$ is much shorter than the magnetic scale length $L_{B}$ at the UHR layer, $\eta$ is given by:

$$
\eta \approx \frac{\omega_{c e} L_{n}}{c \alpha}\left[\sqrt{1+\alpha^{2}}-1\right]^{1 / 2}
$$

where $\alpha=\omega_{p e} / \omega_{c e}$ is evaluated at the UHR layer and $c$ is the velocity of light. As $L_{n}$ becomes shorter, $\eta$ decreases and $C_{\max }$ increases. In order to measure $L_{n}$ at the UHR surface on CDX-U, we acquired electron density data with a Langmuir triple probe and a single vertical chord, microwave interferometer, that were both scanned in major radius. These data are presently being analyzed to estimate $C_{\max }$ for the B-SX-FX emission process to determine if changes of $L_{n}$ at the UHR may explain the observed variation in $\mathrm{T}_{\mathrm{rad}} / \mathrm{T}_{\mathrm{e}}$

Future experiments on CDX-U will use an antenna assembly mounted inside the vacuum that has a smaller effective acceptance angle, in order to reduce the effect of polarization mixing due to reflections. This also has the potential to observe the $\mathrm{EBW}$ emission directly, so that the signal intensity is not complicated by mode conversion and tunneling processes.

Experiments to measure mode-converted EBW emission have also started on NSTX. Initial measurements with a frequency scanning heterodyne radiometer, viewing the second 
ECE harmonic with a notched waveguide antenna, show very little EBW emission at the second EBW harmonic. This result is qualitatively consistent with the large $L_{n}$ measured by a microwave edge reflectometer in similar NSTX discharges. Future mode-converted EBW measurements on NSTX may benefit from the planned exploration of the H-Mode regime, which is characterized by the steep edge density gradients that are necessary for efficient BSX-FX mode conversion.

\section{ACKNOWLEDGMENT}

One of us (GT) would like to thank Dr A. Ram of Massachusetts Institute of Technology for helpful discussions and Dr. J. Wilgen of Oak Ridge National Laboratory for providing the notched waveguide antennas and various technical data. This work was funded by U.S. Department of Energy Contract No. DE-AC02-76-CHO-3073 and by a Department of Energy research grant as part of a program to encourage "Innovations in Magnetic Fusion Energy Diagnostic Systems.” 


\section{References}

1. A.E. Costley, et al., Phys. Rev. Lett. 33, 758 (1974)

2. F. Englemann and M. Curatolo, Nucl. Fusion 13, 497 (1973)

3. C.M. Celata and D.A. Boyd, Nucl. Fusion 17, 735 (1977)

4. M. Bornatici, R. Cano, O. DeBarbieri and F. Engelmann, Nucl. Fusion 23, 1153 (1983)

5. I.B. Bernstein, Phys. Rev., 109, 10 (1958)

6. M. Ono, et al., Princeton Plasma Physics Lab. Report 3225 (1997)

7. P.C. Efthimion, et al., Rev. Sci. Instrum. 70, 1018 (1999)

8. J. Hosea, V. Arunasalam and R. Cano, Phys. Rev. Lett. 39, 408 (1977)

9. J. Preinhaelter and V. Kopecky, J. Plasma Phys. 10, 1 (1973)

10. H.P. Laqua, H.J. Hartfuss, and W7-AS Team, Phys. Rev. Lett. 81, 2060 (1998)

11. J. Spitzer, et al., Fusion Technol. 30, 1337 (1996)

12. H.J. Hartfuss, et al., Plasma Phys. Control. Fusion 39, 1693 (1997)

13. R.H. Dicke, Rev. Sci. Instrum. 17, 268 (1946)

14. J. Delucia, S.C. Jardin and A.M.M. Todd, J. Comput. Phys. 37, 183(1980)

15. J. Menard, R. Majeski, R. Kaita, et al., Phys. Plasmas 6, 2002 (1999)

16. M. Brambilla and T. Krücken, Nucl. Fusion 28, 1813 (1988)

17. S. Nakajima and H. Abe, Phys. Rev. A, 38, 4373 (1988)

18. K.C. Wu, A.K. Ram, A. Bers and S.D. Schultz, Proc. of the $12^{\text {th }}$ Topical Conf. on RF Power in Plasmas, AIP Conf. Proc. 403, AIP, New York, pp. 207-210 (1997)

19. S.D. Shultz, A.K. Ram and A. Bers, to appear in the Proc. of the $17^{\text {th }}$ IAEA Fusion Energy Conf., paper IAEA-F1-CN-69/CDP/13

20. A.K. Ram and S.D. Schultz, Excitation, Propagation, and Damping of Electron Bernstein Waves in Tokamaks, submitted to Phys. Plasmas (May 2000)

21. K. Budden, The Propagation of Radio Waves, (Cambridge University Press, Cambridge, 1985), pp 596-602 


\section{Figure Captions}

\section{Figure 1.}

Schematic diagrams of EBW mode-conversion and tunneling processes; (a) EBW conversion to fast X-mode and (b) EBW conversion to O-mode.

\section{Figure 2.}

Frequency ranges for CDX-U plasma parameters which were typical during the EBW measurements presented in this paper (e.g. $\mathrm{B}_{\mathrm{o}} \sim 2 \mathrm{kG}, \mathrm{I}_{\mathrm{p}} \sim 70 \mathrm{kA},\left\langle\mathrm{n}_{\mathrm{e}}\right\rangle \sim 10^{13} \mathrm{~cm}^{-3}$ and $\left.\mathrm{T}_{\mathrm{eo}} \approx 100 \mathrm{eV}\right)$. The figure shows the frequencies of the first three ECE harmonics $\left(\mathrm{f}_{\mathrm{ce}}\right.$, $\left.2 f_{c e}, 3 f_{c e}\right)$, the right and left hand cutoff frequencies $\left(f_{R}, f_{L}\right)$, the upper hybrid frequency $\left(f_{U H}\right)$ and the electron plasma frequency $\left(f_{p e}\right)$.

\section{Figure 3.}

(a) Schematic diagram of the frequency tunable, 8-12 GHz radiometer, which used a 4-6 GHz YIG local oscillator and a second harmonic 4-18 GHz mixer. (b) The fast scanning radiometer, which used a 7.2-12.4 GHz voltage controlled local oscillator, 2-26 GHz fundamental mixer and a low noise $8-12 \mathrm{GHz}$ pre-amplifier.

\section{Figure 4.}

Time evolution of major CDX-U plasma parameters: (a) plasma current, (b) average electron density measured by a microwave interferometer, (c) edge density measured by a Langmuir triple probe, (d) the edge electron temperature measured by the probe and (e) mode-converted EBW emission at $10.8 \mathrm{GHz}$, a frequency resonant with the ECE second harmonic at the magnetic axis. The two sets of shaded vertical line correspond to the times for which the EBW radiation temperature is compared to the Thomson scattering electron temperature profile in Fig. 5.

\section{Figure 5.}

Comparison of the EBW radiation temperature profile to the Thomson scattering electron temperature profile for the two times indicated by vertical shaded lines in Fig. 4; (a) for the time window $217 \pm 0.5 \mathrm{~ms}$ and (b) for the time window $222 \pm 0.5 \mathrm{~ms}$. 


\section{Figure 6.}

(a) Time evolution of the electron temperature measured by a triple probe located at $2 \mathrm{~cm}$ outside the last closed flux surface $(\mathrm{R}=58 \mathrm{~cm})$ and $(\mathrm{b})$ the evolution of the $11.2 \mathrm{GHz}$ EBW radiation temperature from a location near the plasma axis $(\mathrm{R}=35 \mathrm{~cm})$ during a modulated gas puff injected at the outer edge. Following turn off of the gas puff at the edge, a delay in the reheat at the axis, relative to the edge probe, is clearly evident.

\section{Figure 7.}

Arrival time of the peak of the reheat pulse in the EBW radiation temperature and the time of peak electron temperature at the probe located at $\mathrm{R}=58 \mathrm{~cm}$. The time of the peak of the reheat pulse increases approximately linearly with decreasing minor radius. The data is consistent with the EBW emission source being localized in major radius.

\section{Figure 8.}

Color contour plots of EBW radiation temperature measured by a fast scanning radiometer. The EBW radiometer scans from the plasma axis to the last closed flux and back in $40 \mu \mathrm{sec}$. EBW radiation temperature data are shown for (a) an ohmically heated plasma and (b) for a plasma also heated by high harmonic fast wave (HHFW) heating. (c) The increase in radiation temperature due to HHFW heating, obtained by subtracting (a) from (b).

\section{Figure 9.}

(a) Ratio of the signals from two EBW radiometers averaged over a set of plasma shots with similar current and electron density evolution. The thin gray line is the ratio of the radiometer signals for a set of shots for which both radiometers viewed X-mode polarization. The thick black line is for an average over a set of plasma shots with one radiometer viewing $\mathrm{O}$-mode and the other viewing $\mathrm{X}$-mode. (b) Evolution of the plasma current and line integral density for the two datasets shown in (a). The shaded regions show the standard deviation of the data contributing to the averaged signals. 
(a)

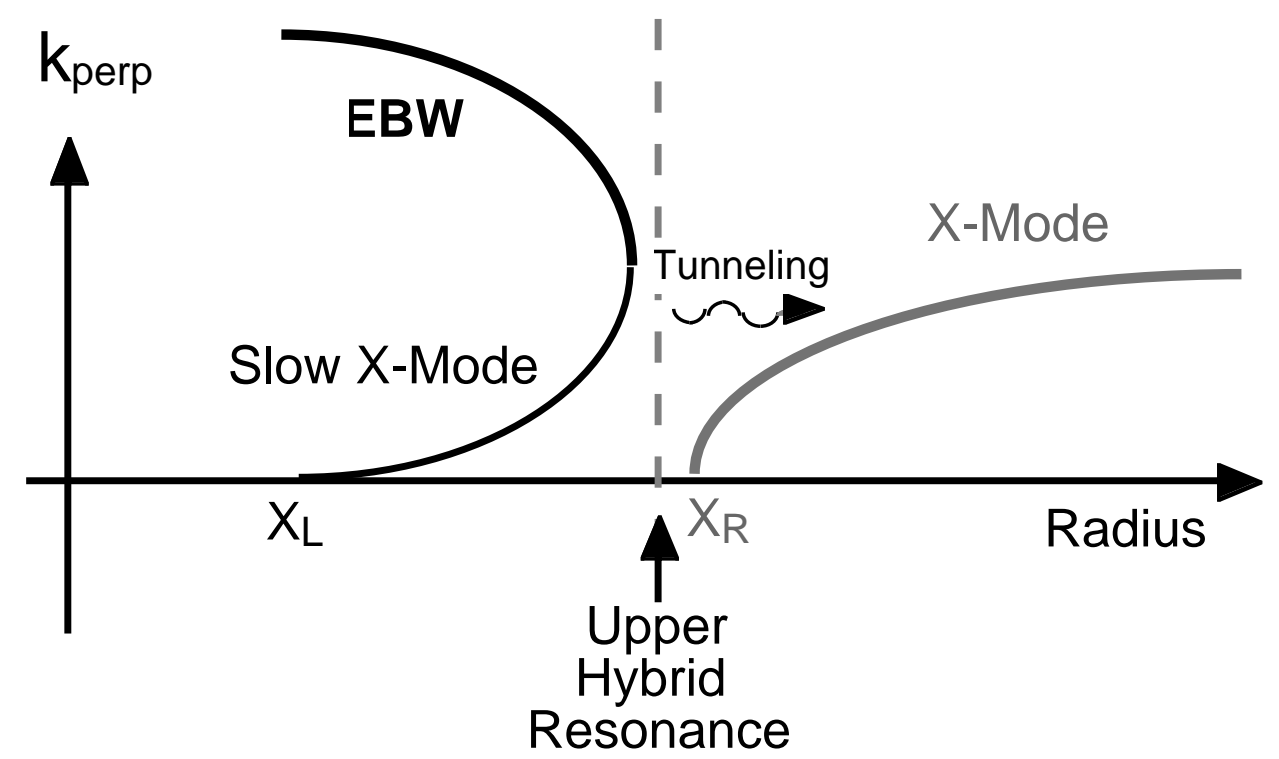

(b)

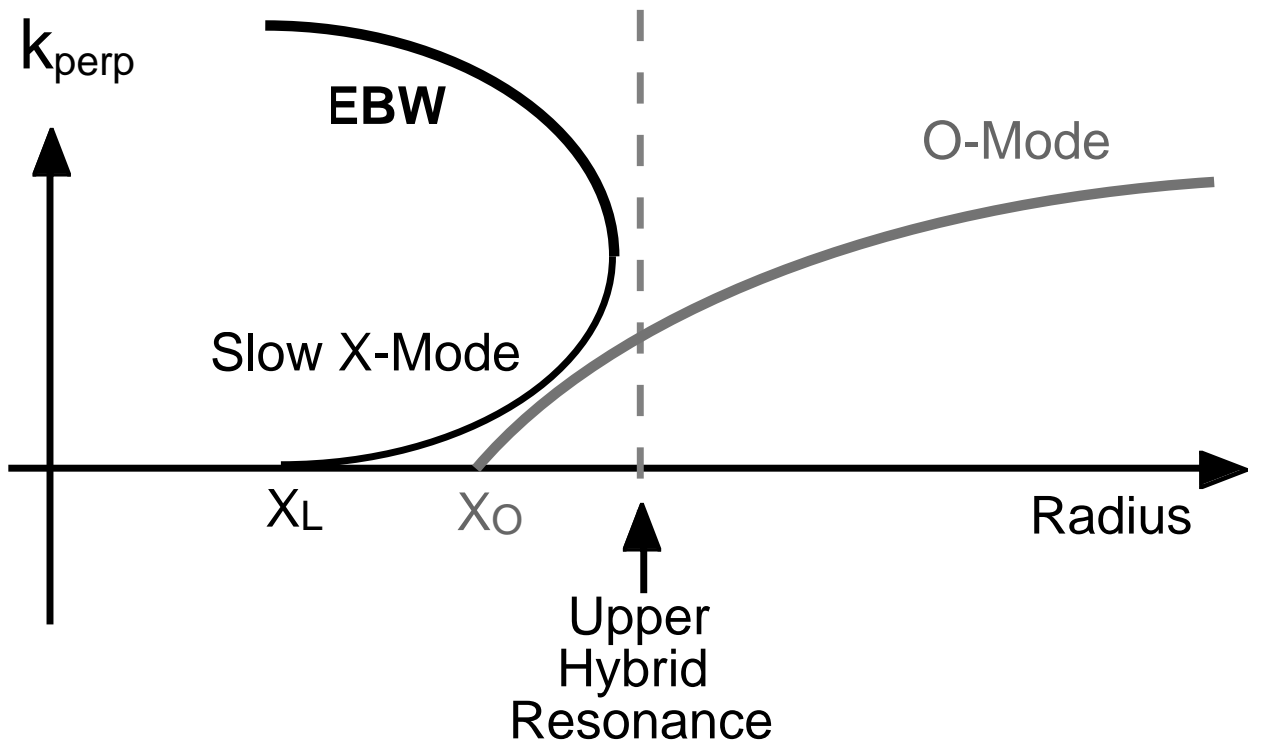

Figure 1. Schematic diagrams of EBW mode-conversion and tunneling processes; (a) EBW conversion to fast X-mode and (b) EBW conversion to O-mode. 


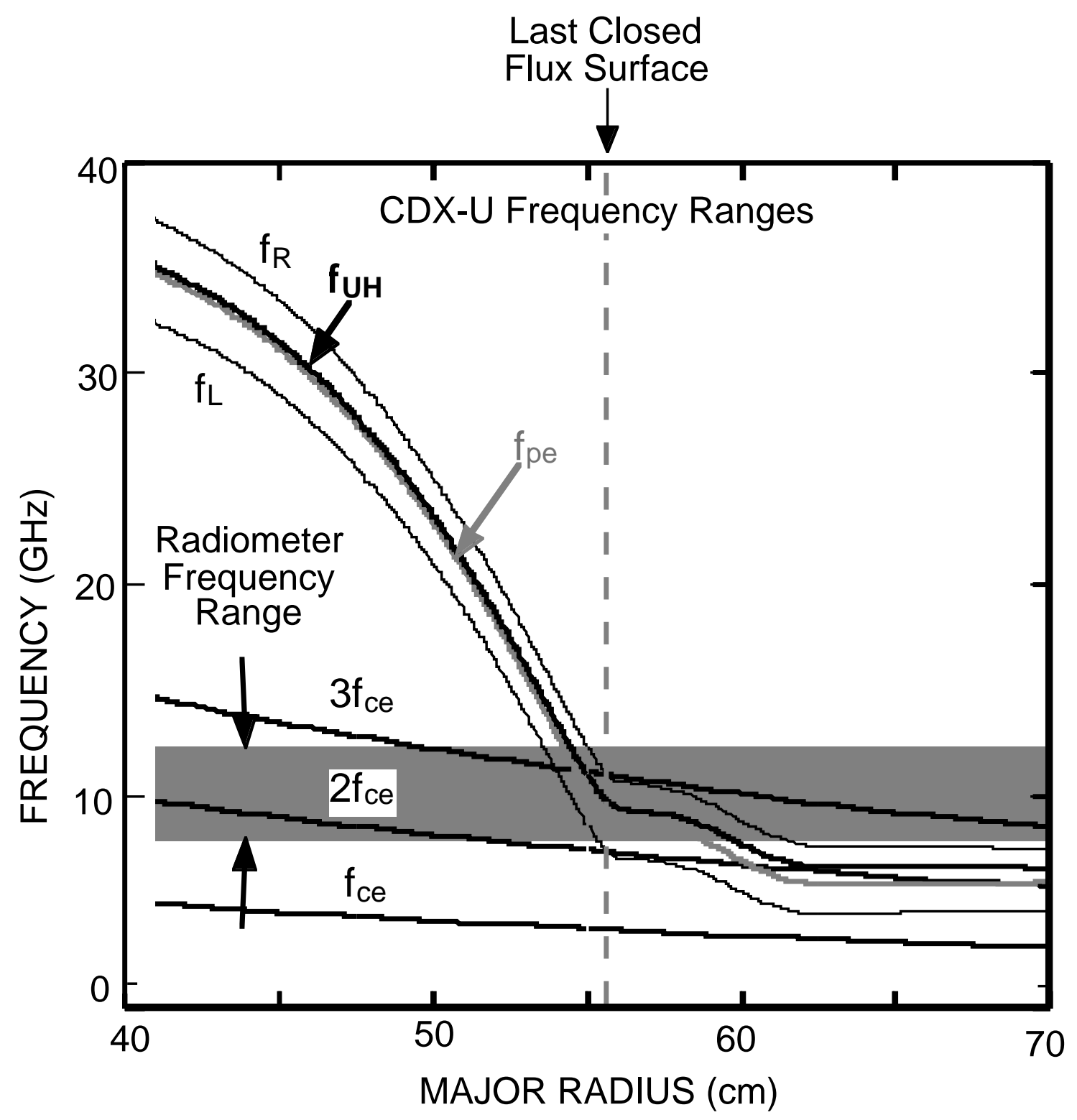

Figure 2. Frequency ranges for CDX-U plasma parameters which were typical during the EBW measurements presented in this paper (e.g. $\mathrm{B}_{\mathrm{o}} \sim 2 \mathrm{kG}, \mathrm{I}_{\mathrm{p}} \sim 70 \mathrm{kA},\left\langle\mathrm{n}_{\mathrm{e}}>\sim 10^{13} \mathrm{~cm}^{-3}\right.$ and $\left.\mathrm{T}_{\mathrm{eo}} \approx 100 \mathrm{eV}\right)$. The figure shows the frequencies of the first three ECE harmonics $\left(\mathrm{f}_{\mathrm{ce}}\right.$, $\left.2 \mathrm{f}_{\mathrm{ce}}, 3 \mathrm{f}_{\mathrm{ce}}\right)$, the right and left hand cutoff frequencies $\left(\mathrm{f}_{\mathrm{R}}, \mathrm{f}_{\mathrm{L}}\right)$, the upper hybrid frequency $\left(\mathrm{f}_{\mathrm{UH}}\right)$ and the electron plasma frequency $\left(\mathrm{f}_{\mathrm{pe}}\right)$. 


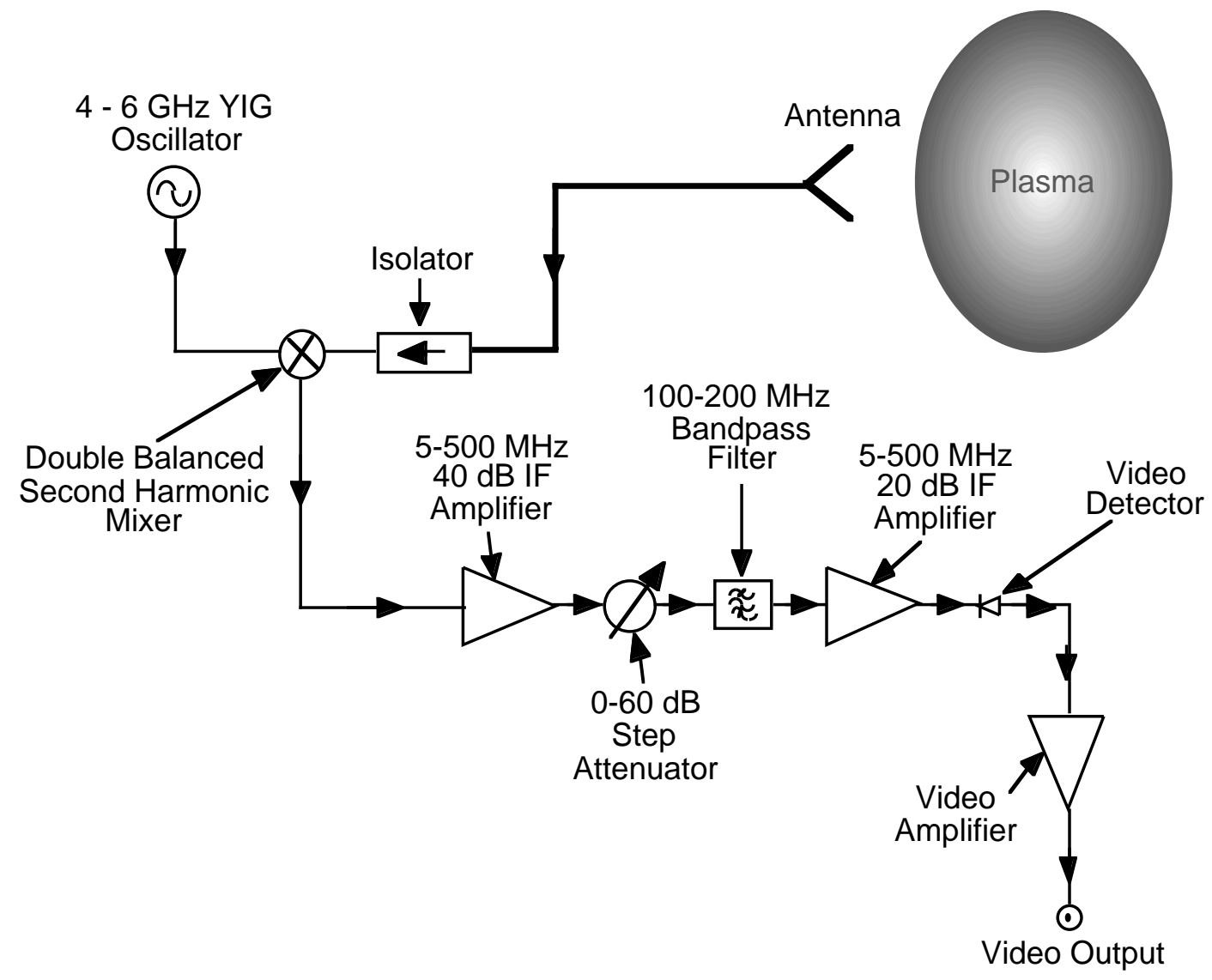

Figure 3(a). (a) Schematic diagram of the frequency tunable, 8-12 GHz radiometer, which used a 4-6 GHz YIG local oscillator and a second harmonic 4-18 GHz mixer. 


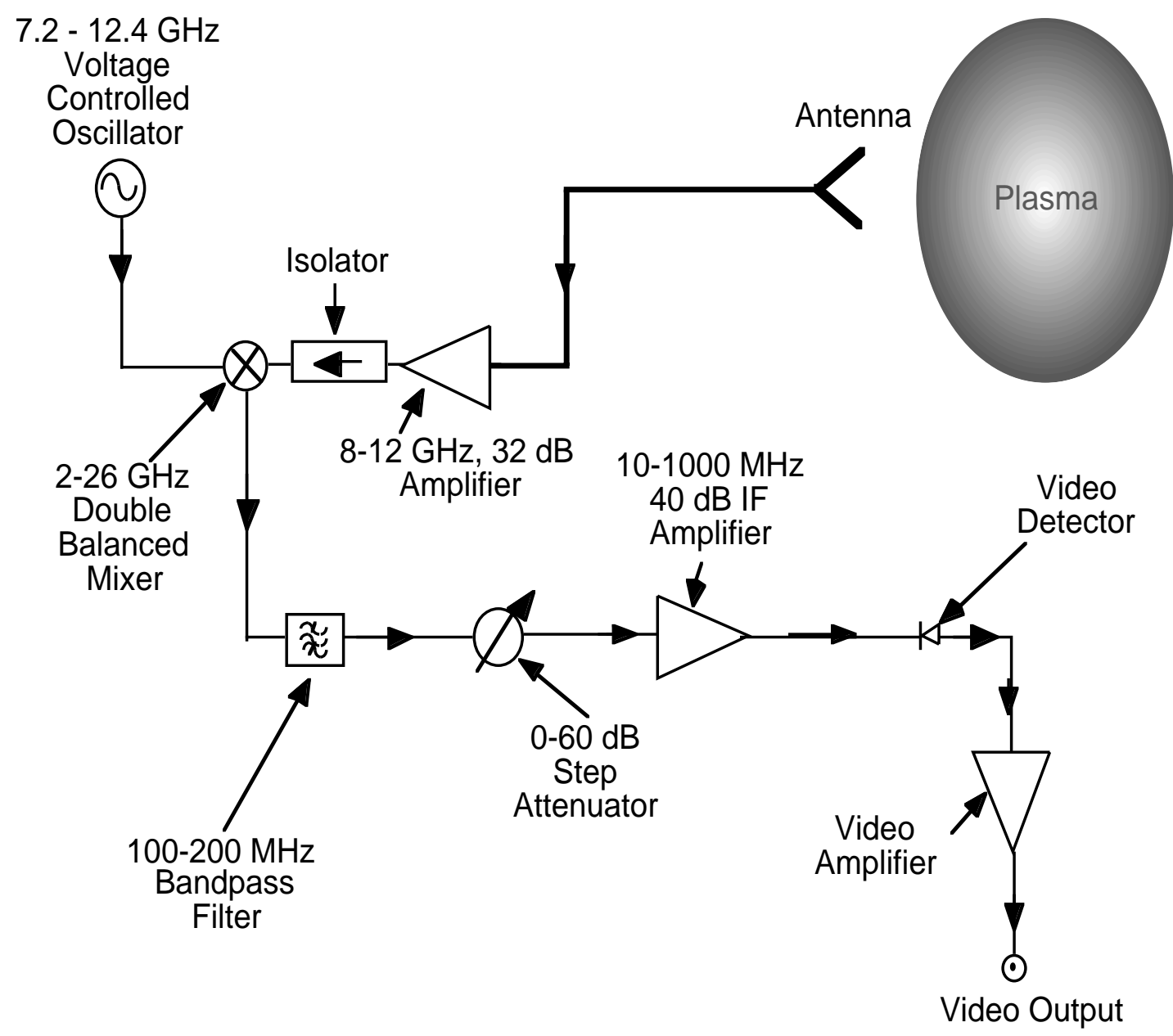

Figure 3(b). (b) The fast scanning radiometer, which used a 7.2-12.4 GHz voltage controlled local oscillator, $2-26 \mathrm{GHz}$ fundamental mixer and a low noise 8-12 GHz preamplifier. 


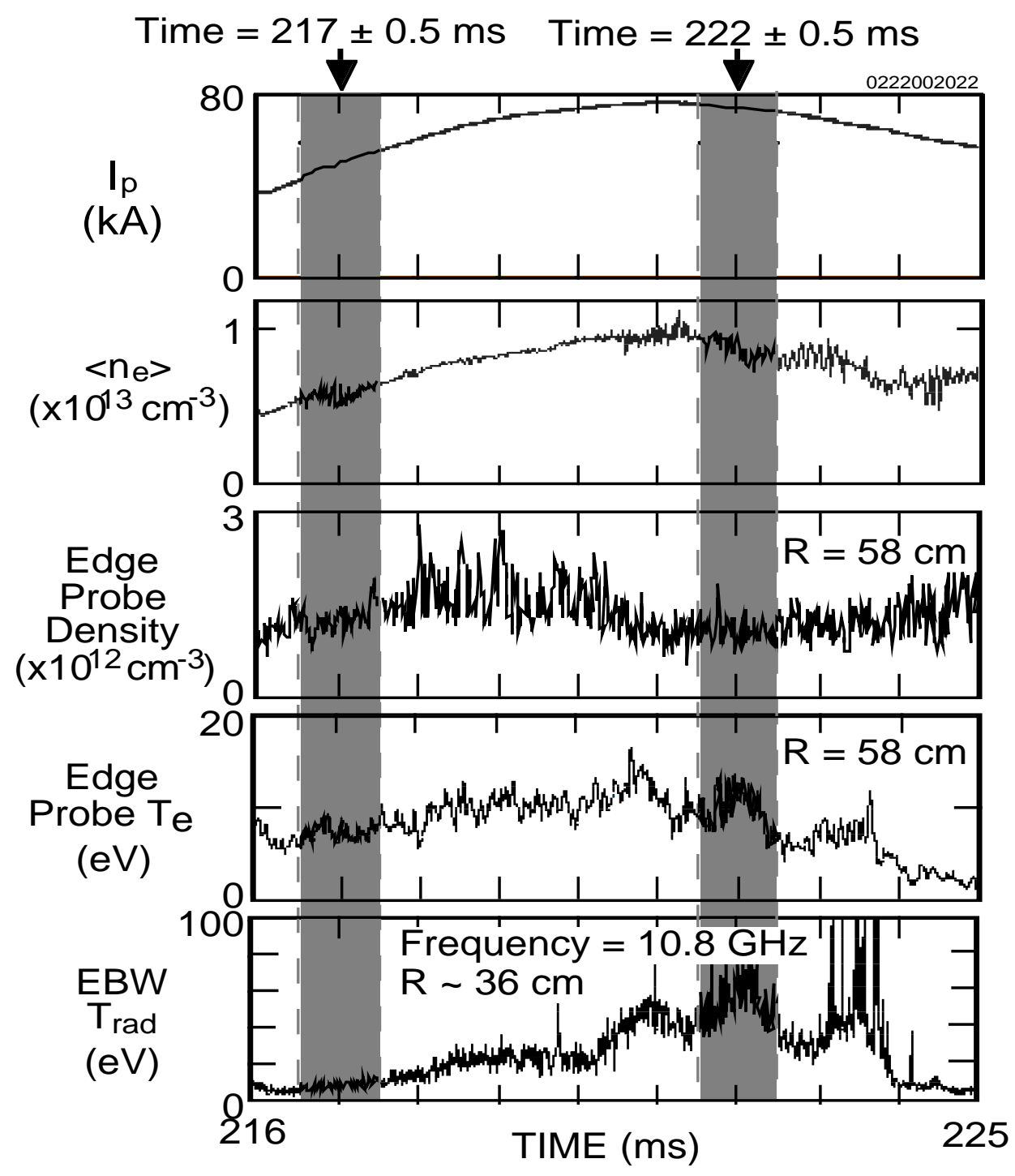

Figure 4. Time evolution of major CDX-U plasma parameters: (a) plasma current, (b) average electron density measured by a microwave interferometer, (c) edge density measured by a Langmuir triple probe, (d) the edge electron temperature measured by the probe and (e) mode-converted EBW emission at $10.8 \mathrm{GHz}$, a frequency resonant with the ECE second harmonic at the magnetic axis. The two sets of shaded vertical line correspond to the times for which the EBW radiation temperature is compared to the Thomson scattering electron temperature profile in Fig. 5. 
(a)

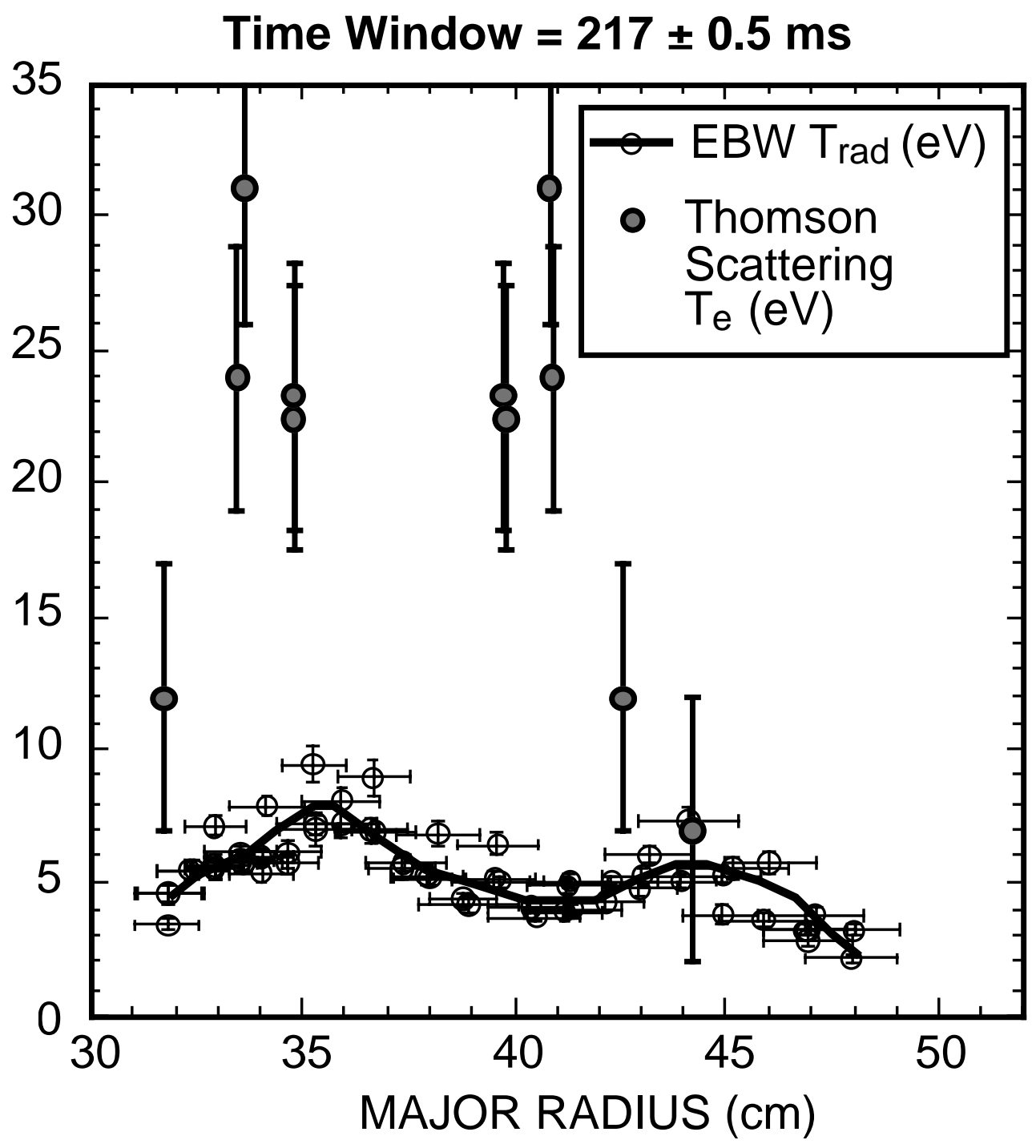

Figure 5(a) Comparison of the EBW radiation temperature profile to the Thomson scattering electron temperature profile for the two times indicated by vertical shaded lines in Fig. 4 for the time window $217 \pm 0.5 \mathrm{~ms}$. 
(b)

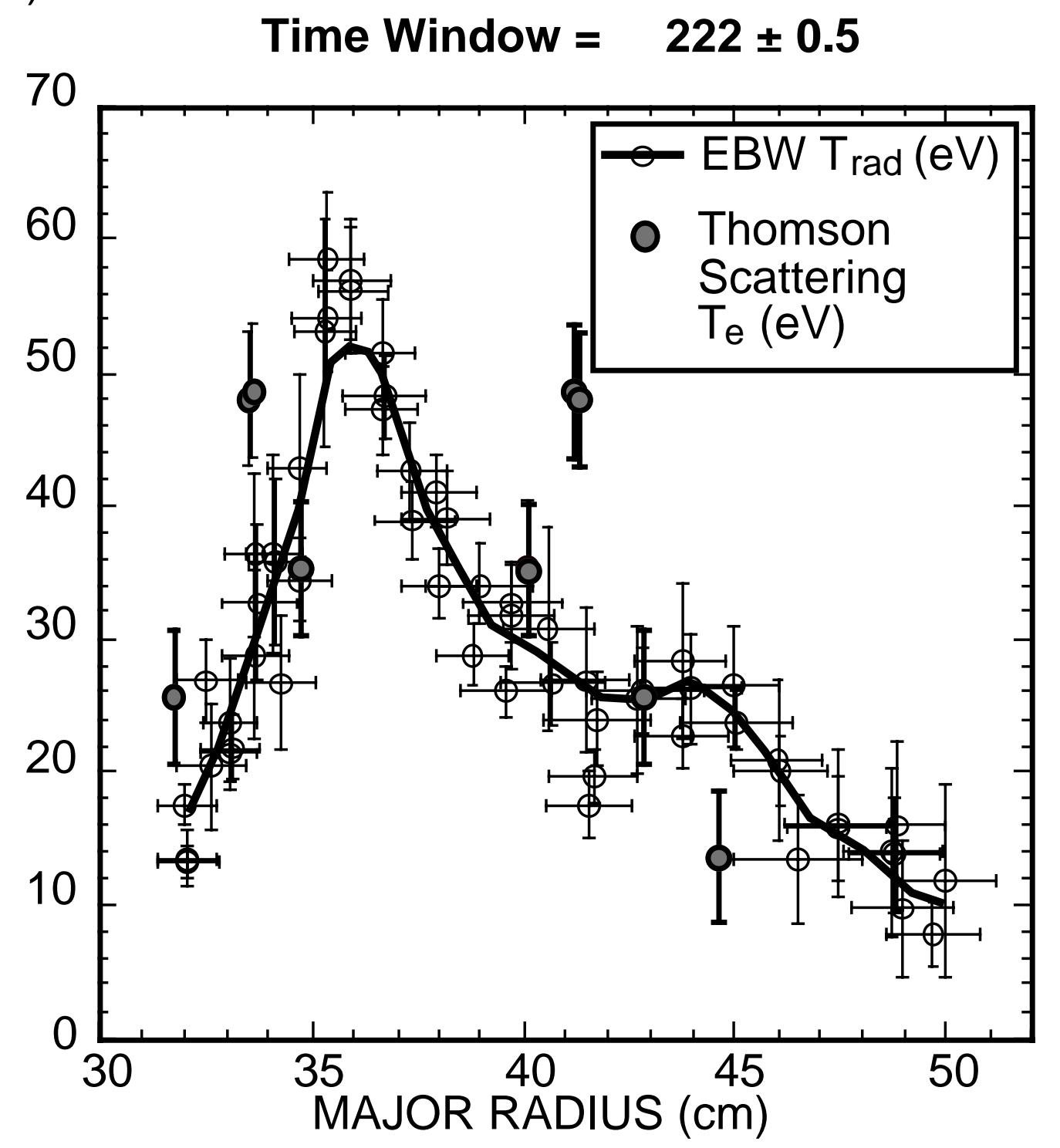

Figure 5(b). Comparison of the EBW radiation temperature profile to the Thomson scattering electron temperature profile for the two times indicated by vertical shaded lines in Fig. 4 for the time window $222 \pm 0.5 \mathrm{~ms}$. 


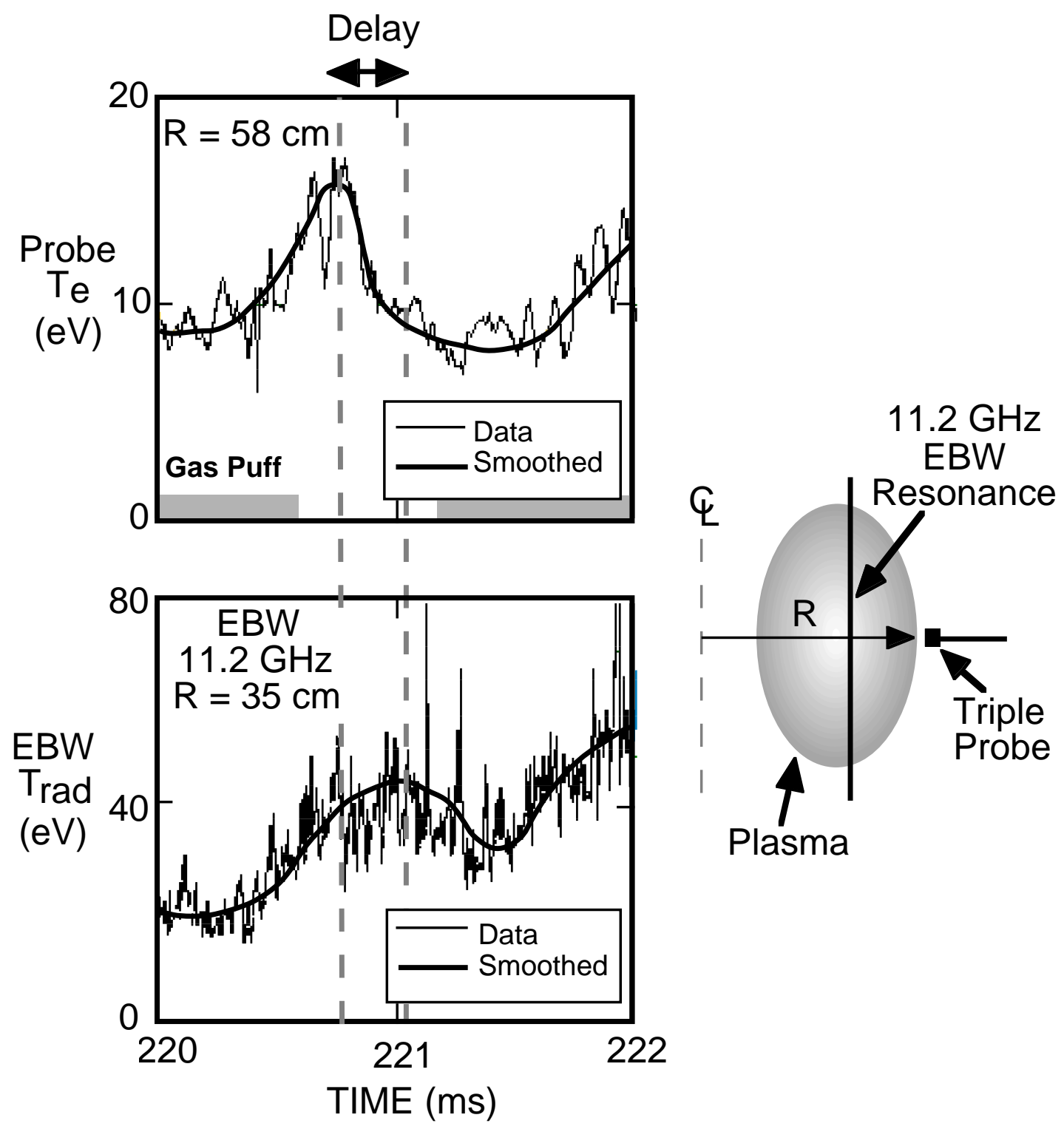

Figure 6. (a) Time evolution of the electron temperature measured by a triple probe located at $2 \mathrm{~cm}$ outside the last closed flux surface $(\mathrm{R}=58 \mathrm{~cm})$ and $(\mathrm{b})$ the evolution of the 11.2 $\mathrm{GHz}$ EBW radiation temperature from a location near the plasma axis $(\mathrm{R}=35 \mathrm{~cm})$ during a modulated gas puff injected at the outer edge. Following turn off of the gas puff at the edge, a delay in the reheat at the axis, relative to the edge probe, is clearly evident. 


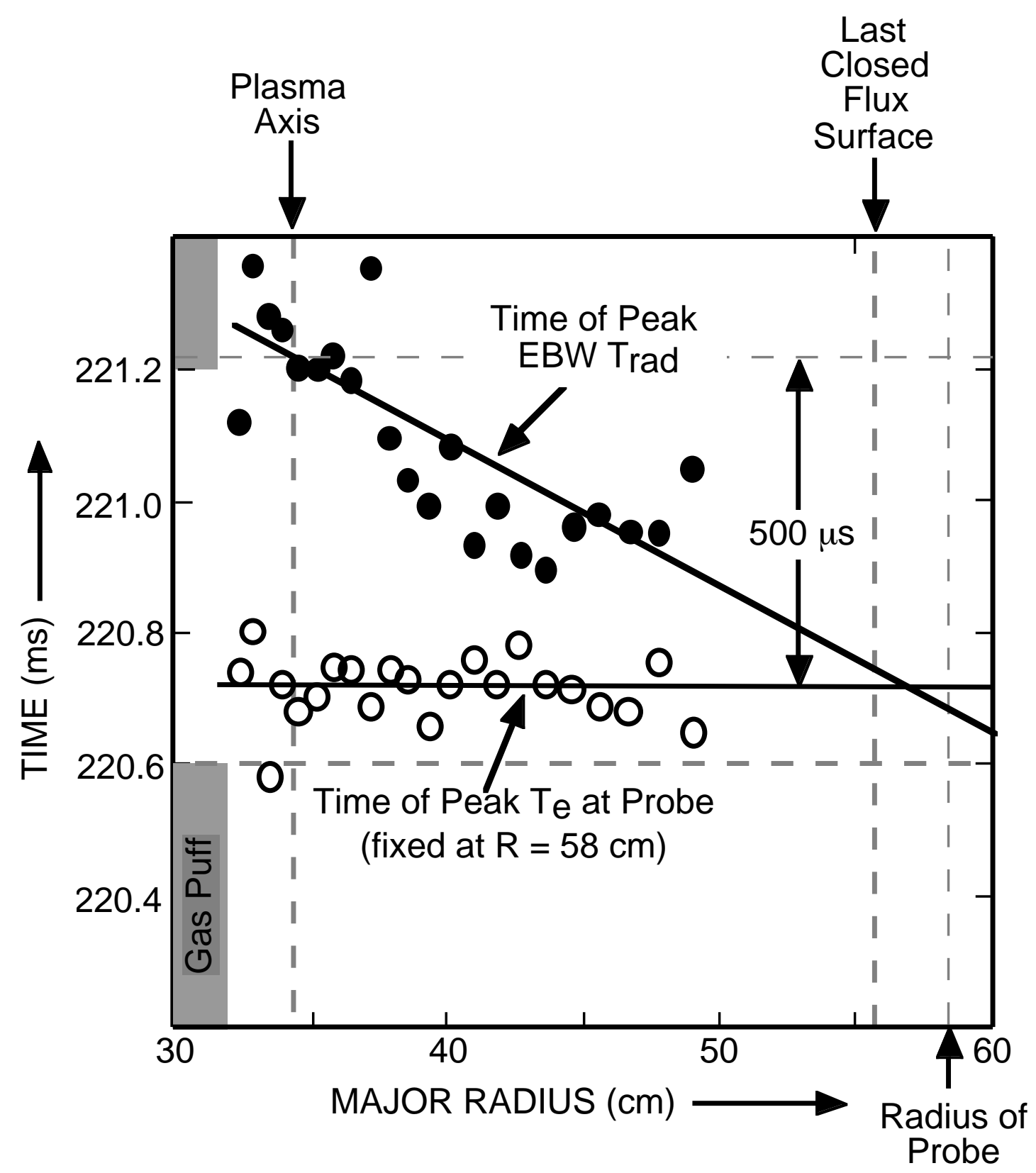

Figure 7. Arrival time of the peak of the reheat pulse in the EBW radiation temperature and the time of peak electron temperature at the probe located at $\mathrm{R}=58 \mathrm{~cm}$. The time of the peak of the reheat pulse increases approximately linearly with decreasing minor radius. The data is consistent with the EBW emission source being localized in major radius. 


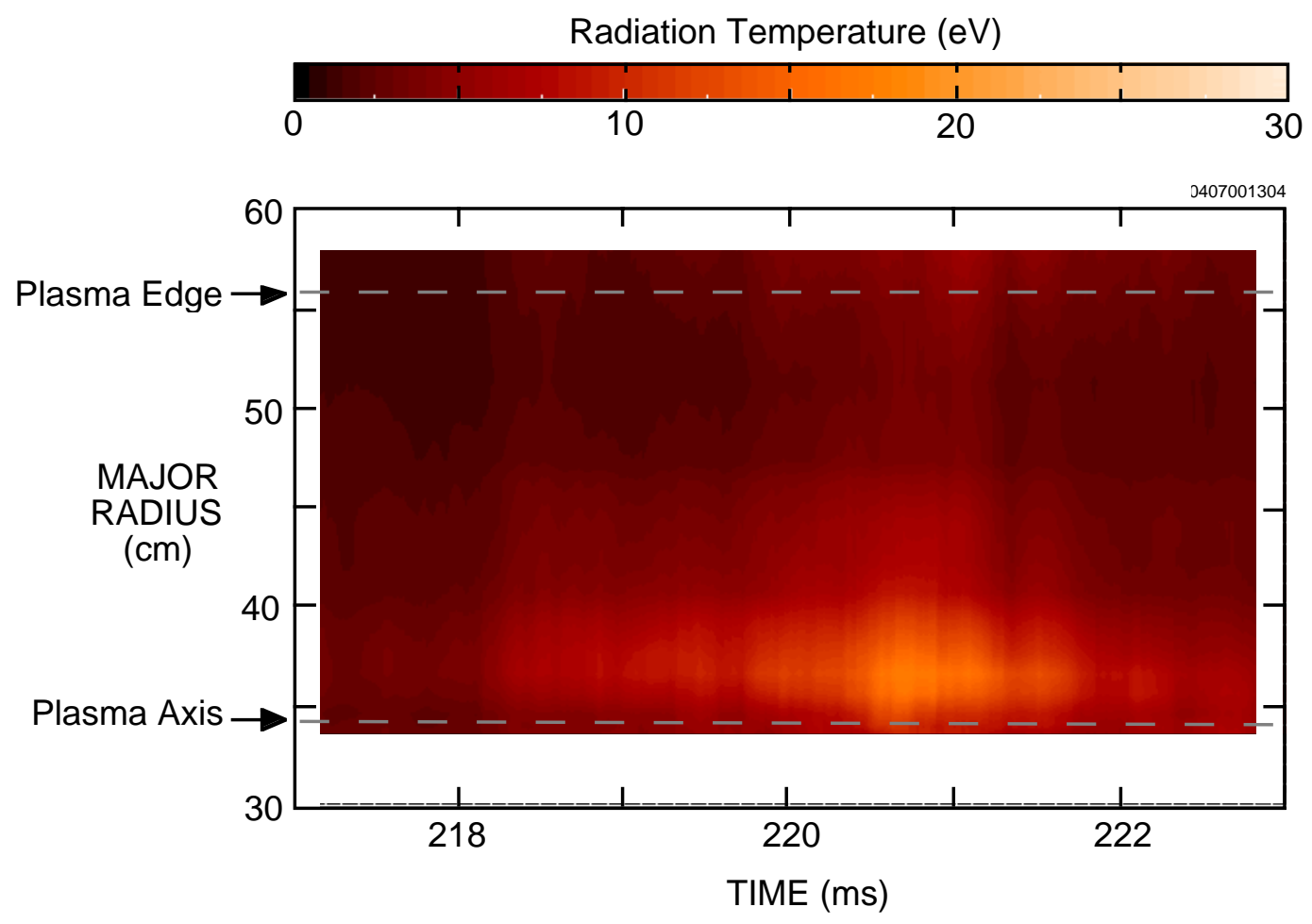

Figure 8(a). Color contour plots of EBW radiation temperature measured by a fast scanning radiometer. The EBW radiometer scans from the plasma axis to the last closed flux and back in $40 \mu \mathrm{sec}$. EBW radiation temperature data are shown for (a) an ohmically heated plasma and (b) for a plasma also heated by high harmonic fast wave (HHFW) heating. (c) The increase in radiation temperature due to HHFW heating, obtained by subtracting (a) from (b). 


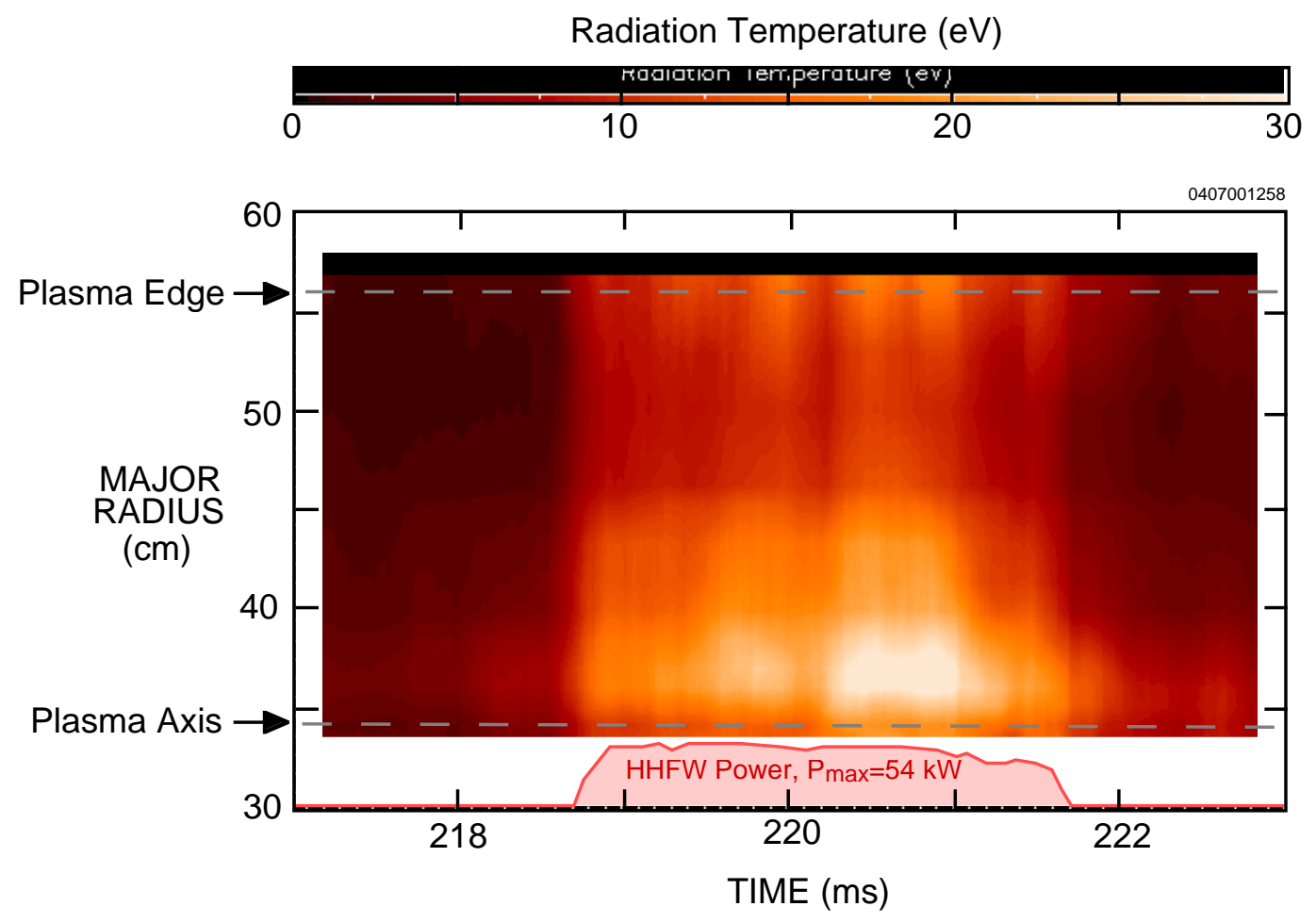

Figure 8(b) 


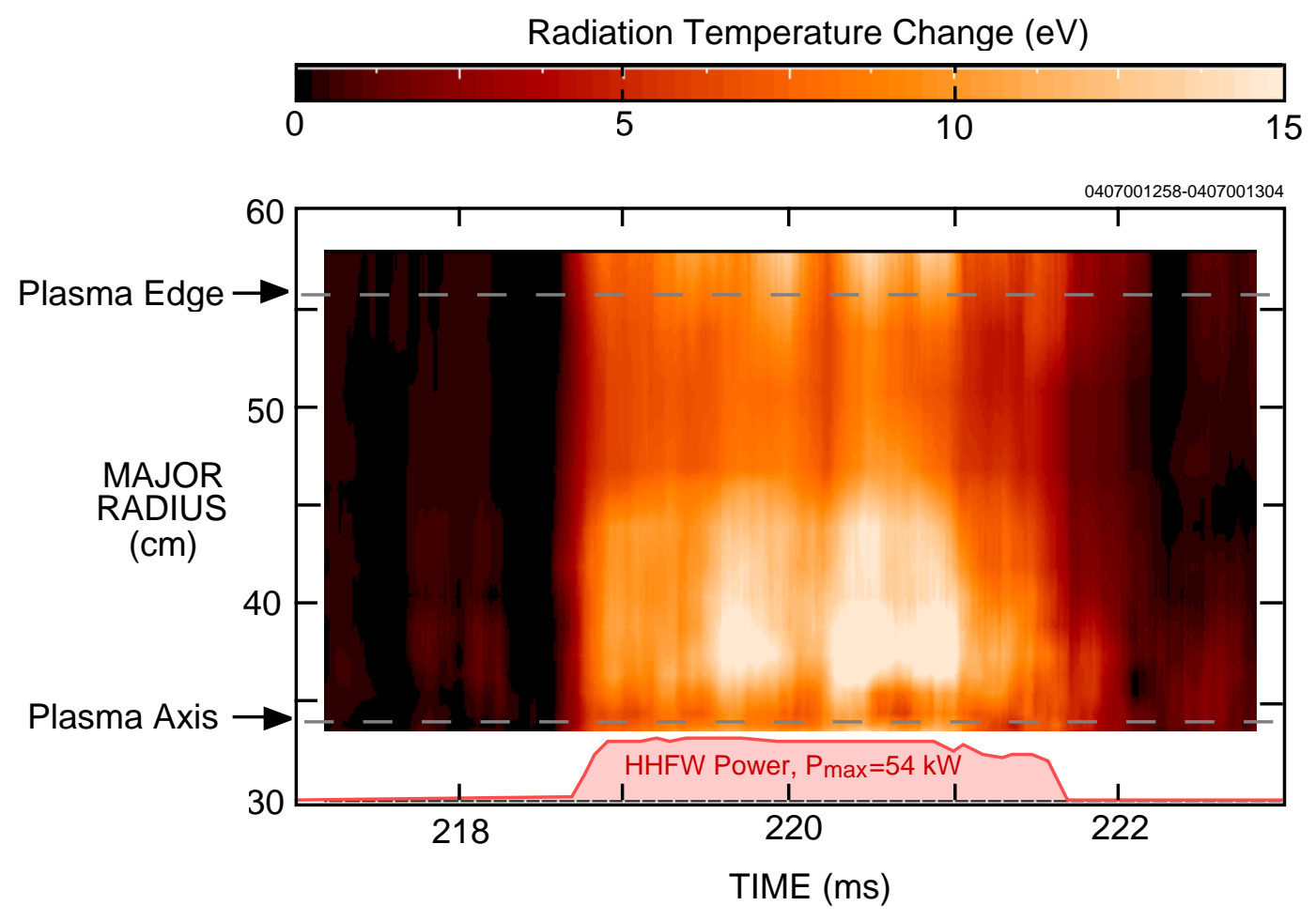

Figure 8(c). 

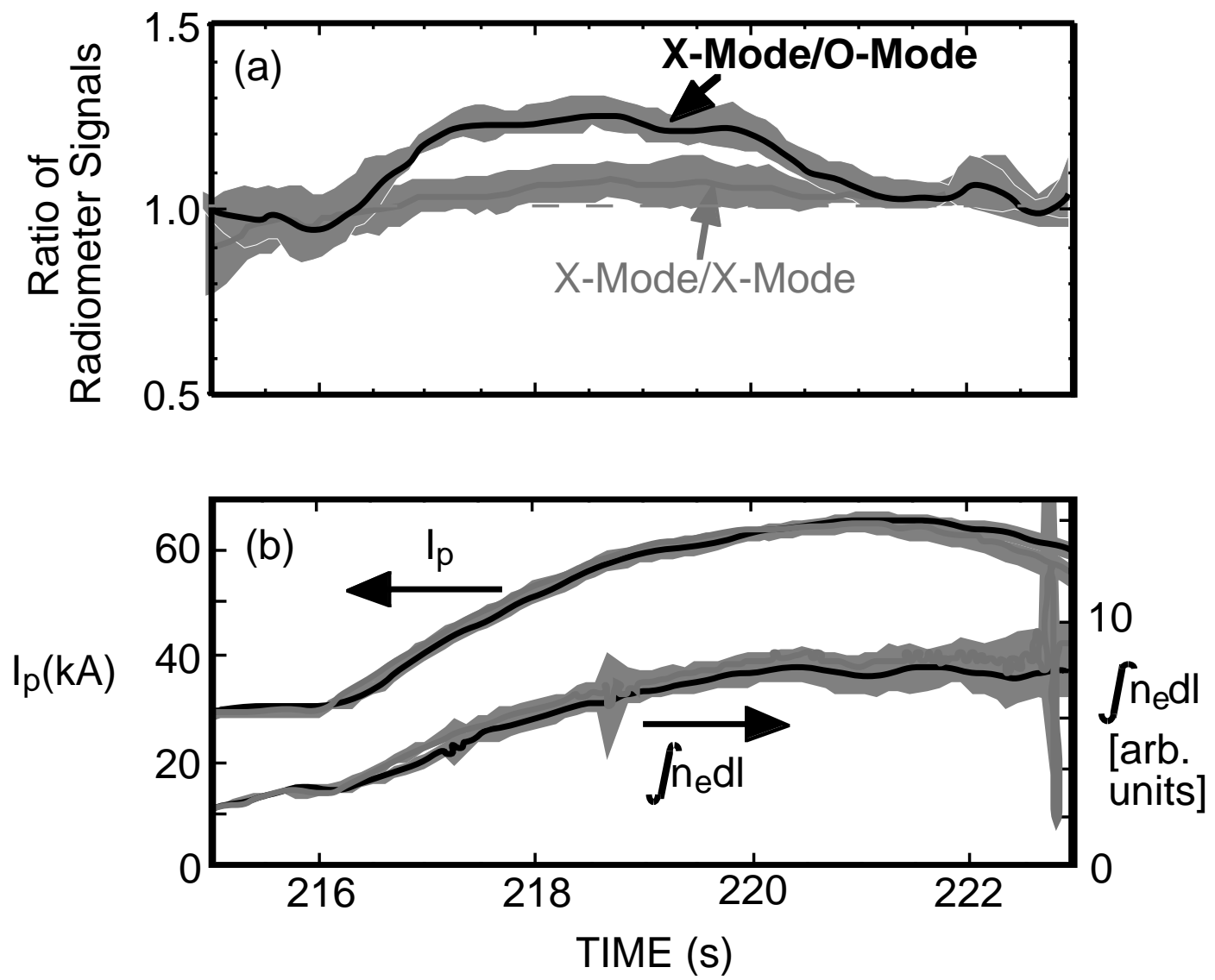

Figure 9. (a) Ratio of the signals from two EBW radiometers averaged over a set of plasma shots with similar current and electron density evolution. The thin gray line is the ratio of the radiometer signals for a set of shots for which both radiometers viewed Xmode polarization. The thick black line is for an average over a set of plasma shots with one radiometer viewing $\mathrm{O}$-mode and the other viewing $\mathrm{X}$-mode. (b) Evolution of the plasma current and line integral density for the two datasets shown in (a). The shaded regions show the standard deviation of the data contributing to the averaged signals. 
The Princeton Plasma Physics Laboratory is operated by Princeton University under contract with the U.S. Department of Energy.

\author{
Information Services \\ Princeton Plasma Physics Laboratory \\ P.O. Box 451 \\ Princeton, NJ 08543
}

Phone: 609-243-2750

Fax: 609-243-2751

e-mail: pppl_info@pppl.gov

Internet Address: http://www.pppl.gov 